\title{
Contributions to ventilation system demand response: a case study of an educational building
}

\author{
Vahur Maask ${ }^{1,2 *}$, Alo Mikola ${ }^{1,3}$, Tarmo Korõtko ${ }^{1,2},{\text { Argo } \text { Rosin }^{1,2} \text {, and Martin Thalfeldt }}^{1,3}$ \\ ${ }^{1}$ Smart City Center of Excellence, Tallinn University of Technology, 19086 Tallinn, Estonia \\ ${ }^{2}$ Department of Electrical Power Engineering and Mechatronics, Tallinn University of Technology, 19086 Tallinn, Estonia \\ ${ }^{3}$ Department of Civil Engineering and Architecture, Tallinn University of Technology, 19086 Tallinn, Estonia
}

\begin{abstract}
The increasing share of volatile renewable energy in the electricity grid increases the importance of load flexibility and Demand Response for balancing electricity supply with demand. Flexible loads in office buildings (e.g. educational buildings) are heating, ventilation, and air conditioning (HVAC) systems. This paper focuses on ventilation systems as flexible loads for providing ancillary services to the grid. A number of studies consider ventilation system control based only on demand or discuss possibilities of improving system performance. Previous studies provide little or no information about ventilation system flexibility, e.g. amount of power modulation, the rate of change, and the duration of how long the power level can be held. The described information is required by aggregators to provide load aggregation services for transmission system operators (TSO). This paper proposes a robust and model-free approach to estimate ventilation system flexibility according to $\mathrm{CO}_{2}$ concentration in extracted air. The proposed approach includes power regulation boundaries for the ventilation system and duration estimation when operating at the selected boundary. A case study is conducted on a ventilation system, which services an auditorium of an educational building. The current paper analyzes the proposed robust approach for estimating ventilation system flexibility and compares estimation to measured results.
\end{abstract}

\section{Introduction}

By introducing distributed volatile renewable energy generation to the electricity grid the balance between electricity supply and demand is becoming difficult to maintain and predict. This is the reason why Demand Response (DR) as a source for energy flexibility is becoming important to provide ancillary services to the grid to maintain system stability. Flexibility can be characterized by the amount of power modulation, the duration of forced power level, the rate of change, the response time, location, etc. [1].

According to the European Commission buildings consume around $40 \%$ of the energy produced in the European Union [2]. In commercial buildings, heating, ventilation, air conditioning, and lighting systems are the biggest energy consumers, where ventilation systems alone account up to $12 \%$ of the overall energy consumption [3]. While the usage of heating, cooling, and lighting is dependent on ambient conditions, their utilization in DR programs can be limited. Nonetheless, the thermal capacity of a building and its use to provide flexibility has been studied in [4], [5]. Ventilation systems on the other hand, are well suited to provide ancillary services to the grid. The load flexibility of ventilation systems is dictated by indoor air quality (IAQ) as it must provide the defined minimum requirements for indoor climate at all times. The standard CEN/TR 16798 states minimum requirements for three main IAQ parameters: $\mathrm{CO}_{2}$ concentration, temperature, and humidity.

The use of ventilation systems for providing load flexibility has been of elevated interest of research. Studies [6], [7] consider temperature based ventilation control to provide grid services. A ventilation system is considered as virtual battery storage in [6] where physics-based thermal models and machine-learning techniques are combined to achieve the required power level. In [7] HVAC system was studied to provide frequency regulation services where it was found that $15 \%$ of the rated fan power can be used to provide grid services without jeopardizing occupants' thermal comfort. The potential use of a ventilation system in DR is discussed in [8], where the authors state that a single $13 \mathrm{~kW}$ ventilation system in a 12 -story apartment building can provide $4.5 \mathrm{~kW}$ of power increase and 1.0 $\mathrm{kW}$ of power reduction when needed without compromising IAQ. Ventilation system shutdown when needed is discussed in [9] where it is found that $\mathrm{CO}_{2}$ concentration has the highest impact on ventilation system flexibility and the minimum duration for a residential building with a space volume of $100 \mathrm{~m}^{3}$ is 5 minutes. Mikola et al. [10], [11] have shown that the $\mathrm{CO}_{2}$-based tracer gas methods are suitable for the ventilation performance evaluation and they have also confirmed that in many cases the fully mixed ventilation is achieved.

\footnotetext{
* Corresponding author: vahur.maask@taltech.ee
} 
The studied literature does not consider all parameters that characterize flexibility and proposed methods for harvesting flexibility are tailored to function in specific systems, which means it is not universally applicable in other types of systems. One mentioned approach was to use machine-learning techniques, but to implement this approach, a vast amount of data is needed. This paper diminishes the lack of research in the given field by proposing a universal, model-free, and robust method to estimate ventilation system flexibility. Mass balance analysis is used to estimate a ventilation system load flexibility based on $\mathrm{CO}_{2}$ concentration. This approach can be used in parallel with machine-learning methods to immediately include the selected ventilation system into an aggregator's portfolio, which can afterward be taken over by artificial intelligence. The paper is organized as follows: in section 2, the experiment setup for conducting the case study and the method for estimating ventilation system flexibility are given, and section 3 discusses the results of the conducted case study.

\section{Method}

This paper is based on a case study conducted in an auditorium of an educational building and the ventilation system servicing it. In this chapter, the equipment used to conduct this case study and the methodology to estimate load flexibility for the ventilation system is covered.

\subsection{Experiment setup}

The case study was carried out in an auditorium of a building at the Tallinn University of Technology. The experiment included a ventilation system that was servicing only the selected auditorium. The floor area of the selected auditorium is $224.5 \mathrm{~m}^{2}$ and the estimated volume of indoor air is $1122.5 \mathrm{~m}^{3}$. The maximum occupancy of the auditorium is 200 persons and the designed ventilation rate is $1.76 \mathrm{~m}^{3} / \mathrm{s}$. The minimum allowable ventilation rate was set by the fan drive frequency of $17 \mathrm{~Hz}$ which is around $0.48 \mathrm{~m}^{3} / \mathrm{s}$.

A pollution source, a $\mathrm{CO}_{2}$ cylinder with accessories to measure and regulate gas flow, was placed in the center of the auditorium. The $\mathrm{CO}_{2}$ cylinder was weighted before and after the experiment to estimate the average $\mathrm{CO}_{2}$ generation rate during the experiment. An air mixing fan was placed close to the $\mathrm{CO}_{2}$ gas outlet to introduce a vertical component into $\mathrm{CO}_{2}$ pollution and to assist in mixing the air (Figure 1). The use of a mixing fan was required due to the low temperature of the injected $\mathrm{CO}_{2}$ gas that does not mix well with indoor air, while the air exhaled by persons is warmer and has better mixing properties. Fresh air is introduced to the auditorium from beneath the floor with multiple fresh air inlets and polluted air is extracted from above with one air duct which can be located in Figure 1 at the right part of the room plan.

IAQ loggers were placed into the auditorium marked as LGR1 to $L G R 13$ that are located at the height of around $0.8 \mathrm{~m}$, except LGR6 that is installed on the extract air outlet at the height of around $3 \mathrm{~m}$. The level of $\mathrm{CO}_{2}$ was measured using the Evikon E6226 measurement unit $\left(\mathrm{CO}_{2}\right.$ level 0 to $\left.10000 \mathrm{ppm}\right)$. These loggers are added to have a better overview of $\mathrm{CO}_{2}$ distribution inside the auditorium, but they are not used to estimate the ventilation system flexibility. Ventilation system flexibility estimations use only a single $\mathrm{CO}_{2}$ concentration sensor located in the extract air duct, which is the preferred placement for such sensors in most ventilation systems. The described flexibility estimation methodology can be applicable for most ventilation systems with minimal investments.

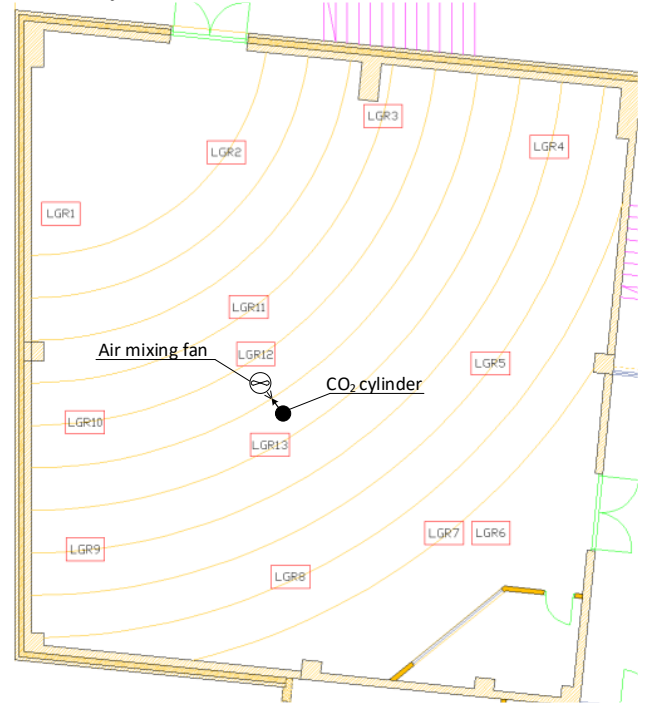

Figure 1. The auditorium and measurement equipment layout.

A mechanical ventilation system is used to change the auditorium air, where two fans are used to supply fresh air and to extract polluted air (Figure 2). The system also includes rotary heat recovery which was set to operate at a maximum rotational speed. The ventilation system also includes air filters, preheating and -cooling of the supply air that are not included in Figure 2.

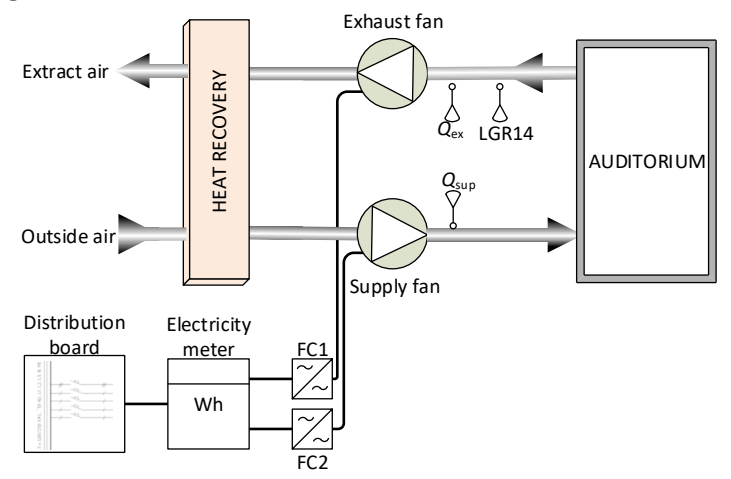

Figure 2. The ventilation system layout with added measurement equipment.

Airflow rates for extract and supply air were measured with a timestep of 1 minute. To measure the airflow, a multifunction indoor air quality meter Testo 435-4 (differential pressure 0 to $250 \mathrm{~Pa}$ and accuracy \pm 1 $\mathrm{Pa}$ ) was used. One IAQ logger was installed into the extract air duct which measures extract air $\mathrm{CO}_{2}$ concentration with a timestep of 1 minute. Each fan 
speed is regulated with frequency converters $F C 1$ and $F C 2$ where each fan drive is powered from the distribution board. Each fan power consumption is measured separately with one electricity meter BFM136. This electricity meter complies with accuracy requirements stated in IEC $62053-22$ for class $0.5 \mathrm{~S}$. The time interval for power consumption measurements is selected to be $2 \mathrm{~min}$.

\subsection{Flexibility prediction}

Two main parameters that need to be predicted for flexibility estimation are (a) the amount of power modulation and (b) the duration of how long the power level can be held. The amount of power modulation can be estimated based on historical data where the assumption that each day the ventilation system is operating with the same load pattern is made. The amount of load modulation can be expressed as the available power increase $P_{\text {inc }}$ or decrease $P_{\text {dec }}$ which can be calculated as follows:

$$
\begin{aligned}
& P_{\text {inc }}=P_{\text {max }}-P_{\mathrm{i}} \\
& P_{\text {dec }}=P_{\mathrm{i}}-P_{\text {min }}
\end{aligned}
$$

where $P_{\max }$ and $P_{\min }$ are ventilation unit power consumption at maximum and minimum ventilation rate which in this study are named as forced ventilation rate (FVR). The power consumption of the ventilation system at the time $i$ is expressed as $P_{\mathrm{i}}$.

The duration for the selected power level is defined by IAQ, where the $\mathrm{CO}_{2}$ concentration is measured to be used in estimations. The standard CEN/TR 16798-2 states limit conditions for IAQ, where the maximum allowable $\mathrm{CO}_{2}$ concentration for educational buildings is around $1100 \mathrm{ppm}$.

A mass balance analysis can be used to estimate $\mathrm{CO}_{2}$ concentration in a space where the assumption is made that $\mathrm{CO}_{2}$ concentration can be expressed as a single variable $C$. The change of $\mathrm{CO}_{2}$ concentration in a given space is dependent on $\mathrm{CO}_{2}$ generation $(G)$, ambient $\mathrm{CO}_{2}$ concentration $\left(C_{0}\right)$, ventilation rate $(Q)$, and the space volume $(V)$. The mass balance equation for mixing ventilation can be expressed as follows [8]:

$$
V \frac{d C}{d t}=G+Q C_{0}-Q C
$$

$\mathrm{CO}_{2}$ generation must be known to estimate ventilation system flexibility. Based on measurements $\mathrm{CO}_{2}$ generation rate can be calculated as shown in (4). This equation is derived from (3) and is put into a discrete form which is more suitable for a control system.

$$
G_{\mathrm{i}}=\frac{V \cdot\left(C_{\mathrm{i}}-C_{\mathrm{i}-1}\right)}{\Delta t}+Q_{\mathrm{i}} \cdot\left(C_{\mathrm{i}}-C_{0}\right)
$$

Knowing the $\mathrm{CO} 2$ generation rate at a given timestep, estimation for ventilation system flexibility according to $\mathrm{CO}_{2}$ concentration can be made as shown in (5). When the ventilation system is working at the minimum ventilation rate to provide power decrease then $\mathrm{CO}_{2}$ concentration starts rising until the upper limit is reached. Therefore, (5) can be used to estimate the duration when the $\mathrm{CO}_{2}$ concentration in a space will reach its boundary. The main restriction for the duration when the ventilation system is operating at lowered power consumption is the upper limit of $\mathrm{CO}_{2}$ concentration. There is no lower limit for $\mathrm{CO}_{2}$ concentration, which means that there is no limitation to increase ventilation system power consumption in the $\mathrm{CO}_{2}$ concentration perspective.

$$
\tau_{\mathrm{i}}=\frac{V \cdot\left(C_{\text {limit }}-C_{\mathrm{i}}\right)}{G_{\mathrm{i}}-Q_{\min } \cdot \frac{C_{\mathrm{i}}+C_{\text {limit }}-2 C_{0}}{2}}
$$

$\mathrm{CO}_{2}$ concentration and airflow measurements can have fluctuations that do not correlate due to disturbances or measurement reading lag. This will cause unrealistic flexibility estimations (e.g. estimated duration for FVR is infinitely long). To have a good estimation, these values must be filtered. In this paper, the maximum duration $\tau_{\max }$ is chosen to be 5 hours, which was selected based on the results of the case study. All estimations that exceed this limit are considered unreasonable and will be replaced by an alternative estimation based on the average $\mathrm{CO}_{2}$ generation during the last 5 minutes, which can be calculated as follows:

$$
\tau_{\mathrm{i}}>\tau_{\max } \Rightarrow G_{\mathrm{i}}=\frac{1}{n} \sum_{k=1}^{n} G_{\mathrm{i}-\mathrm{k}}
$$

The same principle as described previously is used when unexpected negative $\mathrm{CO}_{2}$ generation is detected at times the ventilation system is forced to operate at a minimum rate. The $\mathrm{CO}_{2}$ generation data of the previous 5 minutes will be used to calculate the new duration estimation and also the next $\mathrm{CO}_{2}$ concentration, using (3).

\section{Results}

In this section, results from the power consumption measurement of the selected ventilation system are discussed to estimate the amount of power modulation available at each hour of the day. A case study is conducted to estimate the duration of how long FVR can be held until the $\mathrm{CO}_{2}$ concentration reaches its limit. Based on acquired data the proposed method to estimate the ventilation system flexibility can be studied.

\subsection{Amount of power modulation}

The available amount of power modulation can be estimated statistically based on historical data. In this study, the ventilation system was monitored for one week from $23^{\text {rd }}$ November to $30^{\text {th }}$ November 2020. Results show that the ventilation system is operating 
with the same schedule on all days, including weekends (Figure 3). The ventilation system is scheduled to operate at the maximum rate between 7:00 and 22:00 which means that between this time window ventilation system power consumption can only be decreased. The ventilation system is operating at the minimum rate between 22:00 and 7:00 which means that during this time the ventilation system power consumption can only be increased. Transitions from maximum rate to minimum and vice versa conducted at 7:00 and 22:00 do not happen immediately which causes outliers in the data.

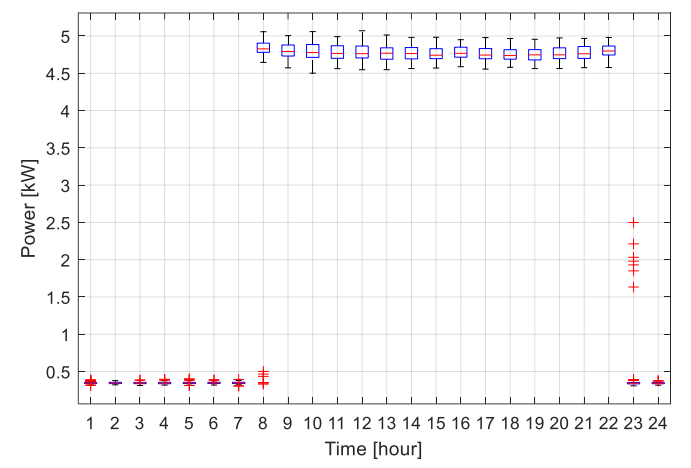

Figure 3. Studied ventilation system power consumption during one day.

During the operation at maximum ventilation rate, the average power consumption of the ventilation system was around $4.77 \mathrm{~kW}$, where the maximum deviation of $0.56 \mathrm{~kW}$ was metered between 9:00 and 10:00. During the operation at the minimum ventilation rate, the average power consumption of the ventilation system was around $0.35 \mathrm{~kW}$, where the deviation between the maximum and minimum value was less than $0.1 \mathrm{~kW}$. Based on the measurements carried out, it can be estimated that the amount of power modulation for the selected system is around $4.42 \mathrm{~kW}$.

\subsection{Case study}

A case study was conducted on the $9^{\text {th }}$ of October, where the ventilation system that services an auditorium of an educational building was switched from normal to minimum operation (Figure 4). The objective was to reduce the power consumption of the system and to estimate the load flexibility. The case study was divided into events where one disturbance caused by the mixing fan was added (Table 1).

The average power consumption of the ventilation system before switching it to the minimum rate was around $4.88 \mathrm{~kW}$ which corresponds to the airflow rate of approximately $1.79 \mathrm{~m}^{3} / \mathrm{s}$. Calculated specific fan power (SFP) before the FVR was around 2,73 $\mathrm{kW} /\left(\mathrm{m}^{3} / \mathrm{s}\right)$. During operation at the FVR, the system power consumption was around $0.34 \mathrm{~kW}$, which corresponds to the airflow rate of approximately 0.48 $\mathrm{m}^{3} / \mathrm{s}$. Calculated SFP at the FVR was around 0,71 $\mathrm{kW} /\left(\mathrm{m}^{3} / \mathrm{s}\right)$. According to the standard EN 13779, SFP should be less than $2.0 \mathrm{~kW} / /\left(\mathrm{m}^{3} / \mathrm{s}\right)$, which means that the ventilation system has poor efficiency at maximum ventilation rate. The ventilation system took around 90 seconds to reach from one power level to another which means that the rate of power change was approximately $50 \mathrm{~W} / \mathrm{s}$.

Table 1. The case study events and schedule.

\begin{tabular}{|c|c|c|}
\hline Event & Description & Time \\
\hline I & $\begin{array}{c}\text { Start of the experiment, } \mathrm{CO}_{2} \text { gas } \\
\text { injection into the auditorium }\end{array}$ & $11: 52$ \\
\hline II & $\begin{array}{c}\text { The ventilation system is switched to the } \\
\text { minimum rate }\end{array}$ & $12: 44$ \\
\hline III & $\begin{array}{c}\text { Start of the disturbance, the } \mathrm{CO}_{2} \text { gas } \\
\text { mixing fan is switched off }\end{array}$ & $13: 03$ \\
\hline IV & $\begin{array}{c}\text { End of the disturbance, the } \mathrm{CO}_{2} \text { gas } \\
\text { mixing fan is switched on }\end{array}$ & $13: 14$ \\
\hline V & $\begin{array}{c}\text { The maximum allowable } \mathrm{CO}_{2} \\
\text { concentration of 1100 ppm reached }\end{array}$ & $13: 39$ \\
\hline VI & $\begin{array}{c}\text { End of the experiment, the ventilation } \\
\text { system is returned to normal operation }\end{array}$ & $13: 46$ \\
\hline
\end{tabular}

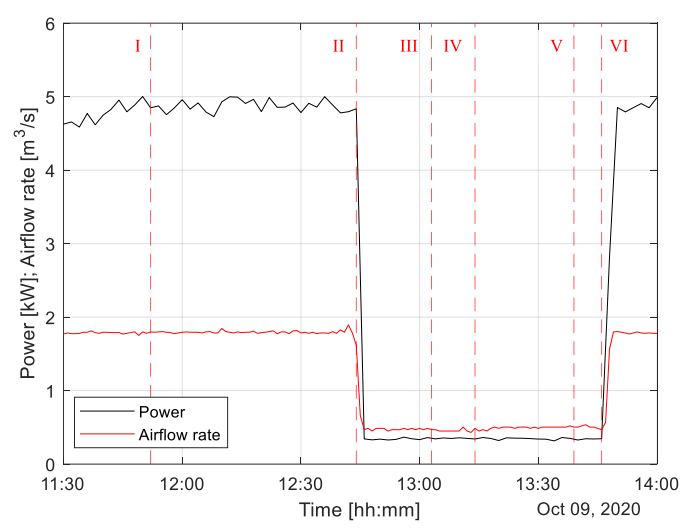

Figure 4. The ventilation system power consumption and airflow rate during the experiment.

The experiment started at 11:52 with the opening the valve for the $\mathrm{CO}_{2}$ cylinder (Figure 5). During the experiment, the $\mathrm{CO}_{2}$ gas flow rate into the auditorium was kept around $22 \mathrm{l} / \mathrm{min}$ which is roughly equal to the $\mathrm{CO}_{2}$ generated by 66 persons, which corresponds to $33 \%$ of room usage. At 12:44, the ventilation system was switched to operate at the FVR. The time before this action was used to stabilize the $\mathrm{CO}_{2}$ concentration in the auditorium and to estimate the time duration of how long the ventilation system can be held at the minimum rate. At 13:03 the mixing fan for $\mathrm{CO}_{2}$ gas was switched off and at 13:14 its operation was restored. This caused a temporary decrease of $\mathrm{CO}_{2}$ concentration in extract air, which was the result of poor $\mathrm{CO}_{2}$ gas mixing in the auditorium air. The flexibility estimation algorithm identified this event as an unexpected negative $\mathrm{CO}_{2}$ generation rate and started to calculate the $\mathrm{CO}_{2}$ concentration in the auditorium based on the $\mathrm{CO}_{2}$ generation data of the previous 5 minutes. This part of the algorithm is only activated when the ventilation system is forced to operate at a certain rate that is below normal operating condition to achieve a decreased power consumption.

The boundary for $\mathrm{CO} 2$ concentration was reached at 13:39 after which the ventilation system operated for 7 minutes at the lowest rate. At 13:46, the ventilation system was set to operate at the normal rate and the 
valve for the $\mathrm{CO}_{2}$ cylinder was closed, which marked the end of the experiment. Poor mixing of the $\mathrm{CO}_{2}$ gas with the air inside the auditorium resulted in a high $\mathrm{CO}_{2}$ concentration. The build-up of the $\mathrm{CO}_{2}$ concentration is not expected when the $\mathrm{CO}_{2}$ is generated by people inside the auditorium instead of a gas dispensing system.

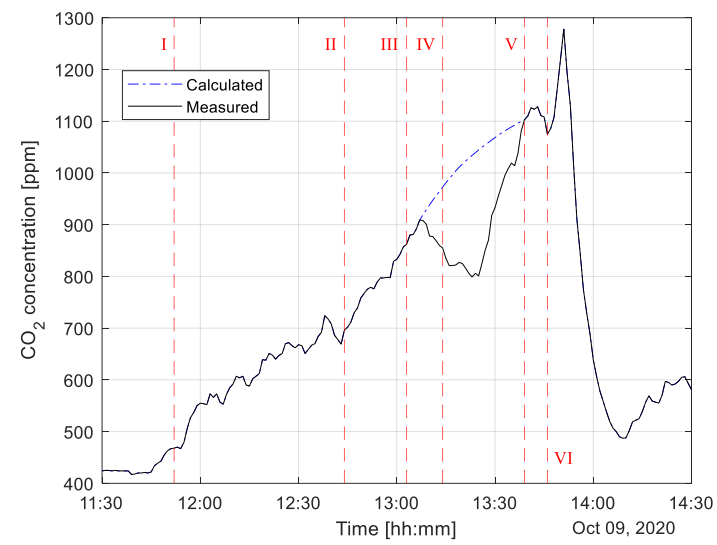

Figure 5. $\mathrm{CO}_{2}$ concentration in extract air during the experiment.

The amount of power modulation achieved in the experiment in accordance with the analytical estimation shown in Figure 3. The duration of the period where the $\mathrm{CO}_{2}$ concentration reached or exceeded boundary conditions was around 55 minutes. The estimated duration which was calculated at 12:44 was around 53 minutes, which means that the error of the estimation was 2 minutes or $4 \%$. The initial estimation method for reduced operation duration produced fluctuating results, which is why a moving-average filter was implemented (Figure 6). The window of length of the filter was set to 3 minutes that smoothed larger fluctuations and did not cause significant lag from the initial estimation. The measured duration shows how much time was left until the $\mathrm{CO}_{2}$ concentration boundary was reached from the start of the FVR. At 13:07, the algorithm detected an unexpected negative $\mathrm{CO}_{2}$ generation rate, which meant that the $\mathrm{CO}_{2}$ concentration level was estimated and the measurements did not affect the duration estimation.
The estimated $\mathrm{CO}_{2}$ concentration reached the boundary of $1100 \mathrm{ppm}$ before it was measured which is why the estimations are lower than measured results.

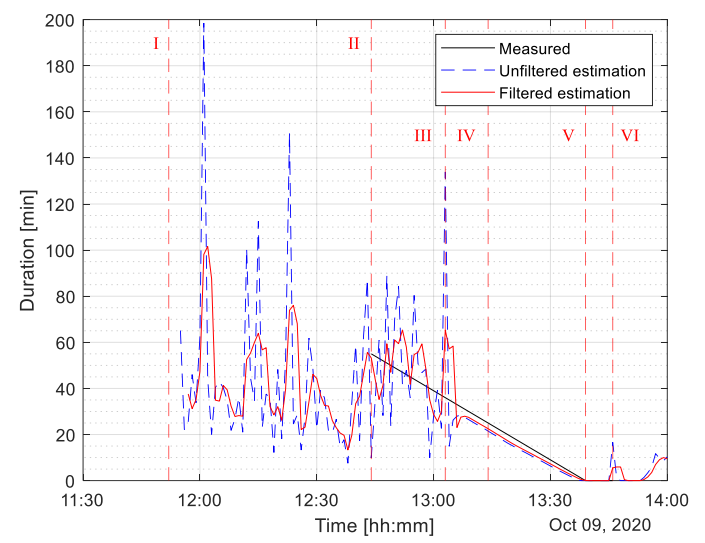

Figure 6. Measured and estimated durations for forced ventilation rate.

In this paper, IAQ loggers located inside the auditorium were used to have an overview of conditions in the auditorium during the experiment. During normal operation, it was found that there is a weak positive correlation with a coefficient of approximately 0.48 between the $\mathrm{CO}_{2}$ concentration measured inside the extract air duct and the average $\mathrm{CO}_{2}$ concentration inside the auditorium. It can be seen from Figure 7 that during the ventilation system normal operation the extract air $\mathrm{CO}_{2}$ concentration was in the range of $\mathrm{CO}_{2}$ concentration inside the auditorium measured in multiple points. During the period when the ventilation system operated at the $\mathrm{FVR} \mathrm{CO}_{2}$ concentration measured inside the extract air duct and average $\mathrm{CO}_{2}$ concentration inside the auditorium did not correlate, which can be also seen from Figure 7. This can be caused by poor mixing of $\mathrm{CO}_{2}$ gas in the auditorium or inertia between the auditorium and the extracted air measurements. To have a better understanding of the reasons this experiment should be repeated with real persons, where thorough planning and ethical reasons should be addressed.

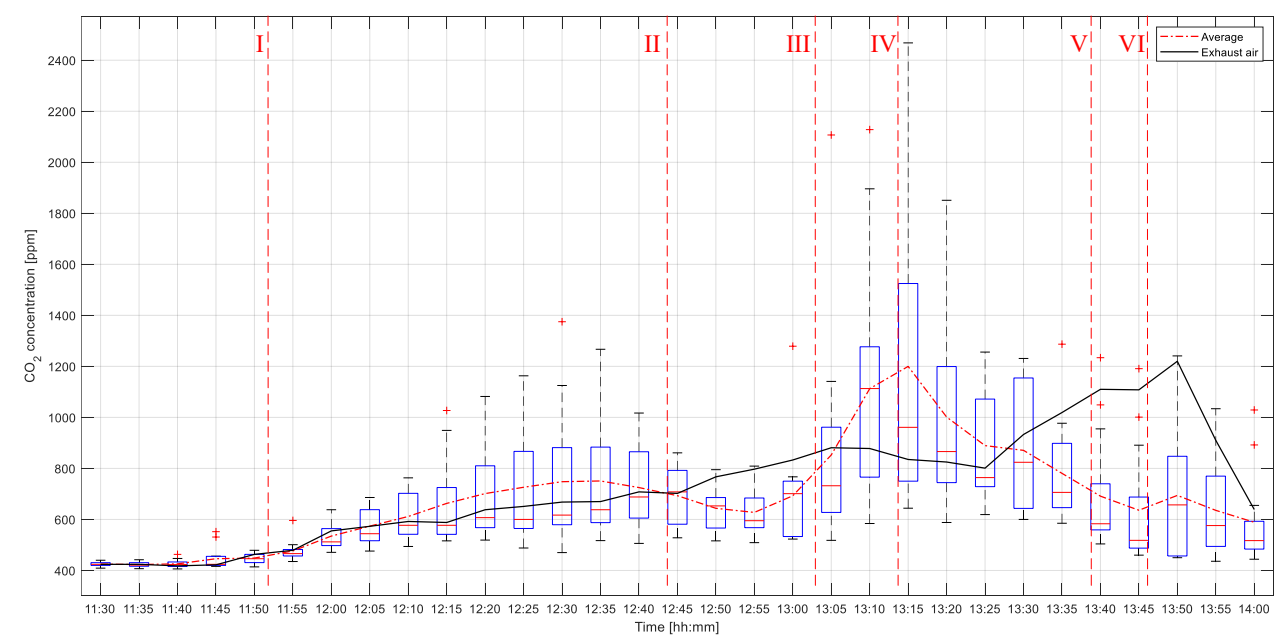

Figure 7. $\mathrm{CO}_{2}$ concentration in the auditorium and the extract air. 


\section{Conclusion}

In this paper, a method to estimate ventilation system load flexibility was proposed. To test the method, a case study was conducted in one auditorium of an educational building, where air exchange was provided by one ventilation system. The case study included the investigation of ventilation system power consumption, the impact of FVR on the $\mathrm{CO}_{2}$ concentration, and how it affects flexibility. Three main flexibility parameters were considered: the amount of power modulation, the rate of change, and the duration how of long the minimum power level can be held.

The amount of power change was estimated with statistical analysis and it is found that during measurements ventilation system operated at two scheduled power levels. During daytime or working hours the ventilation system is operating at the maximum ventilation rate which corresponds to approximately $4.77 \mathrm{~kW}$. During night hours the ventilation system operates at the minimum rate and the power consumption is around $0.35 \mathrm{~kW}$. This means that available power modulation is around $4.42 \mathrm{~kW}$, but according to the schedule, the ventilation system power consumption can only be decreased during the daytime. The rate of change was measured during the experiment and it is found to be around $50 \mathrm{~W} / \mathrm{s}$ for the selected system.

The duration of how long FVR can be held is based on mass balance analysis. Firstly, the $\mathrm{CO}_{2}$ generation is calculated based on the extract air $\mathrm{CO}_{2}$ concentration change, airflow rate, and space volume. Secondly, based on the calculated $\mathrm{CO}_{2}$ generation rate estimation for the duration is made. High fluctuations and unrealistic estimations are filtered out. The experiment showed that with $33 \%$ of auditorium usage the ventilation system can operate at the minimum rate for $55 \mathrm{~min}$ while the estimated duration was around $53 \mathrm{~min}$. To keep the developed method robust and applicable for different ventilation systems, only one $\mathrm{CO}_{2}$ sensor in the extract air duct of the ventilation system is used, thus the developed method does not consider non-uniformity in $\mathrm{CO}_{2}$ concentration. It is the distinct aim of the authors to avoid the limitation of the developed method to only selected ventilation systems, due to alternating locations of the $\mathrm{CO}_{2}$ sensor. Based on the results, the proposed method can be used to estimate ventilation system flexibility.

Future work considers more ventilation systems and buildings to have a higher amount of available power to regulate. Typically, ventilation systems are configured to operate according to building occupancy, thus to have sufficient load flexibility available, commercial and residential buildings should be combined. In the study pollution source was $\mathrm{CO}_{2}$ gas which was injected into the auditorium from the gas cylinder, but in further studies, heaters should be added to introduce conditions that are closer to reality. Method to estimate duration will be improved by considering the inertia in $\mathrm{CO}_{2}$ concentration, adding historical data to the estimation, and including multi-zone ventilation systems, where estimations can be based on the highest $\mathrm{CO}_{2}$ concentration zone. Also, changing the $\mathrm{CO}_{2}$ concentration limit according to a space size, air exchange type, and airflow rate should be addressed in further studies.

This work was supported by Estonian Centre of Excellence in Zero Energy and Resource Efficient Smart Buildings and Districts ZEBE, grant 2014-2020.4.01.15-0016 funded by European Regional Development Fund. This work has also been supported by the European Commission through the H2020 project Finest Twins (grant No. 856602).

\section{References}

[1] Eurelectric, "Flexibility and aggregation - requirements for their interaction in the market," 2014. [Online]. Available:

http://www.eurelectric.org/media/115877/tf_balagr_report_final_je_as-2014-030-0026-01-e.pdf.

[2] European Commission, "Energy performance of buildings directive."

https://ec.europa.eu/energy/topics/energyefficiency/energy-efficient-buildings/energyperformance-buildings-directive_en (accessed Jan. 15, 2021).

[3] I. Drovtar, J. Niitsoo, A. Rosin, J. Kilter, and I. Palu, "Electricity consumption analysis and power quality monitoring in commercial buildings," PQ 2012 8th Int. Conf. - 2012 Electr. Power Qual. Supply Reliab. Conf. Proc., pp. 107-112, 2012.

[4] T. Häring and A. Rosin, "Thermal Modelling of a Control Center for Flexibility Analysis in nZEB Nanogrids," in 2020 IEEE 61 th International Scientific Conference on Power and Electrical Engineering of Riga Technical University (RTUCON), 2020, pp. 1-6.

[5] M. B. Sanjareh, M. H. Nazari, G. B. Gharehpetian, R. Ahmadiahangar, and A. Rosin, "Optimal scheduling of HVACs in islanded residential microgrids to reduce BESS size considering effect of discharge duration on voltage and capacity of battery cells," Sustain. Energy, Grids Networks, vol. 25, pp. 1-15, 2021.

[6] J. Wang, S. Huang, D. Wu, and N. Lu, "Operating a commercial building HVAC load as a virtual battery through airflow control," IEEE Trans. Sustain. Energy, vol. 12 , no. 1 , pp. 158-168, 2021.

[7] H. Hao, Y. Lin, A. S. Kowli, P. Barooah, and S. Meyn, "Ancillary Service to the grid through control of fans in commercial Building HVAC systems," IEEE Trans. Smart Grid, vol. 5, no. 4, pp. 2066-2074, 2014.

[8] S. Rotger-Griful, R. H. Jacobsen, D. Nguyen, and G. Sørensen, "Demand response potential of ventilation systems in residential buildings," Energy Build., vol. 121, pp. 1-10, 2016.

[9] V. Maask, T. Haring, R. Ahmadiahangar, A. Rosin, and T. Korotko, "Analysis of ventilation load flexibility depending on indoor climate conditions," Proc. IEEE Int. Conf. Ind. Technol., pp. 607-612, 2020.

[10] A. Mikola, J. Rehand, and J. Kurnitski, "Air change efficiency of room ventilation units," E3S Web Conf., vol. 111, pp. 1-8, 2019.

[11] A. Mikola, T.-A. Kõiv, J. Rehand, and H. Voll, "The Usage of CO2 Tracer Gas Methods for Ventilation Performance Evaluation in Apartment Buildings," 2017, pp. 27-28. 